Session 2168

\title{
VIRTUAL LABORATORY MODULES FOR UNDERGRADUATE STRENGTH OF MATERIALS COURSE
}

\author{
Anant R. Kukreti \\ University of Cincinnati \\ Musharraf Zaman \\ Kurt Gramoll \\ Ji-Hoon Lee \\ University of Oklahoma
}

\begin{abstract}
Virtual laboratory experiments can be a useful self-learning and teaching tool for Strength of Materials. Three modules (Material Module, Bending Module, and Torsion Module) were developed and integrated with the engineering core course (ENGR 2153) offered during the Spring semester each year by the College of Engineering at the University of Oklahoma. An overview of these modules is presented in this paper. An informal evaluation of the impact of these modules was conducted. The results of this evaluation are briefly discussed.
\end{abstract}

\section{INTRODUCTION}

Strength of Materials (ENGR 2153), a sophomore-level engineering core course at the I University of Oklahoma (OU), is taught Spring semester each year as one section with typical enrollment of 60 to 80 students. Although taught exclusively by the School of Civil Engineering and Environmental Science (CEES), students from Civil, Environmental, Pre-Architecture, Petroleum and Industrial Engineering take this course. One of the primary objectives of the course is to introduce the concept of stresses, strains and displacements in structures and their components due to different types of loads. The perception is that if one can determine these quantities for all types of loads, including the loads that cause failure, one will have a complete picture of the mechanical behavior of these structures (Gere and Timoshenko, 1997). An understanding of mechanical behavior is essential for the safe design of all types of structures, whether airplanes and antennas, buildings and bridges, machines and motors, or ships and spacecrafts. The contents of the Strength of Materials course at OU can be divided into the following three broad categories: (1) Material Behavior: Stress, stress transformations, strain, strain transformations, stress-strain relationships, and laboratory procedures to obtain mechanical properties of materials. (2) Member Behavior: Stresses and deformations in various types of members including axial, torsional, bending, transverse shear, and members under combined 
loading. (3) Special Topics: Pressure vessels, buckling of columns, and deflection of beams and other structural members.

Stresses and deflections that govern the design of structures and structural members are usually determined from equations and formulas that are based on the theoretical concepts or theories and mechanical properties of the associated materials. Even if an advanced theory is used to determine the deflection of a beam, for example, the computed deflections cannot be used in practical design unless the mechanical properties (Young's modulus in this case) of the materials are accurately determined. Such properties are available only after careful experiments have been carried out in the laboratory. Furthermore, many practical problems are not amenable to theoretical analyses alone, and in such cases physical simulation is a necessity. For these and other reasons, it is useful to have a laboratory component in teaching the Strength of Materials course effectively. Unfortunately many undergraduate programs in the country, including our program in CEES, does not have this option available because of the large class size.

A cost-effective approach to providing laboratory experience to undergraduate students is to create a "virtual laboratory" (Sun, et al., 2000). An exponential growth in the computer software industry in recent years and availability of user-friendly software package programs have created a unique opportunity for engineering educators to develop virtual laboratory modules and to integrate them into relevant undergraduate courses. To this end, three virtual laboratory experiment modules were developed for selected topics taught in the Strength of Materials course, which included: Material Module, Beam Bending Module, and Torsion Module. These modules are being integrated into the course. An overview of these modules is presented in this paper. Also, the results of a preliminary survey conducted to assess the impact of these modules are presented briefly.

The College of Engineering $(\mathrm{CoE})$ at $\mathrm{OU}$ has implemented a major change in its teaching pedagogy for undergraduate courses. Since Fall semester of 1998, each student entering the CoE as a freshman is required to purchase or lease a laptop computer equipped with the wireless networking capabilities. Classrooms are being upgraded to include facilities for network connections, and courses are being restructured, as appropriate, to introduce computer applications through the use of computer-based teaching tools and a interactive learning modules (Kukreti, 1996; Zaman and Kukreti, 2000). Development of the virtual laboratory modules is an important step in restructuring the Strength of Materials course at OU.

\section{MATERIAL MODULE}

This module is designed to illustrate the load-deformation behavior of selected engineering materials under tensile loading. Typical stress-strain data obtained from actual tension tests on five selected metals, namely, titanium, tempered steel, aluminum, carbon steel and cast iron, are used as the basis of this module. By clicking on the top left window (Figure 1) the user can display the stress-strain graph of the desired material in the right window. The actual stressstrain values used to construct the graph can be displayed on the two small windows ( $\sigma$ and $\gamma$ ) below the graph by clicking on any selected point. The stress-strain data can be displayed in a tabular form (Figure 2) by clicking on the "chart" icon in Figure 1. To avoid over crowding, data for only ten points are displayed in the window at a time (Figures 2 and 3). The graph reappears 

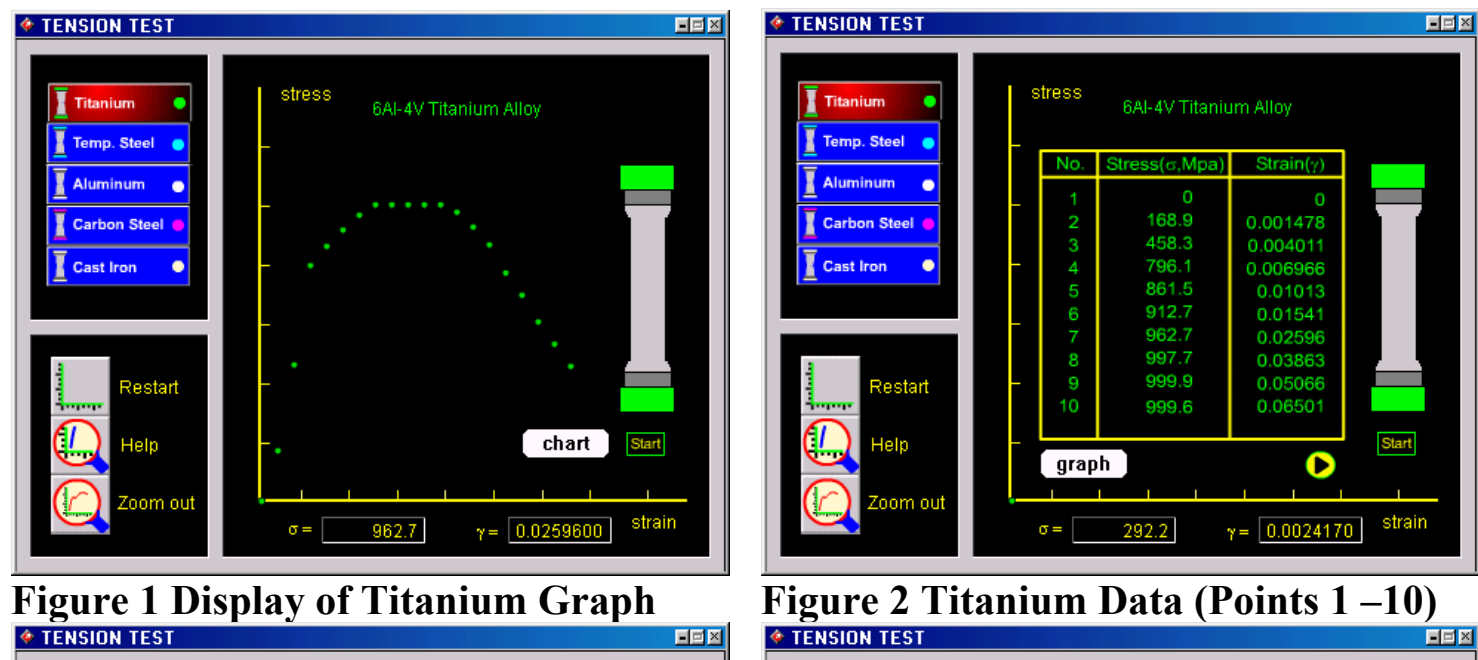

Figure 2 Titanium Data (Points 1 -10)
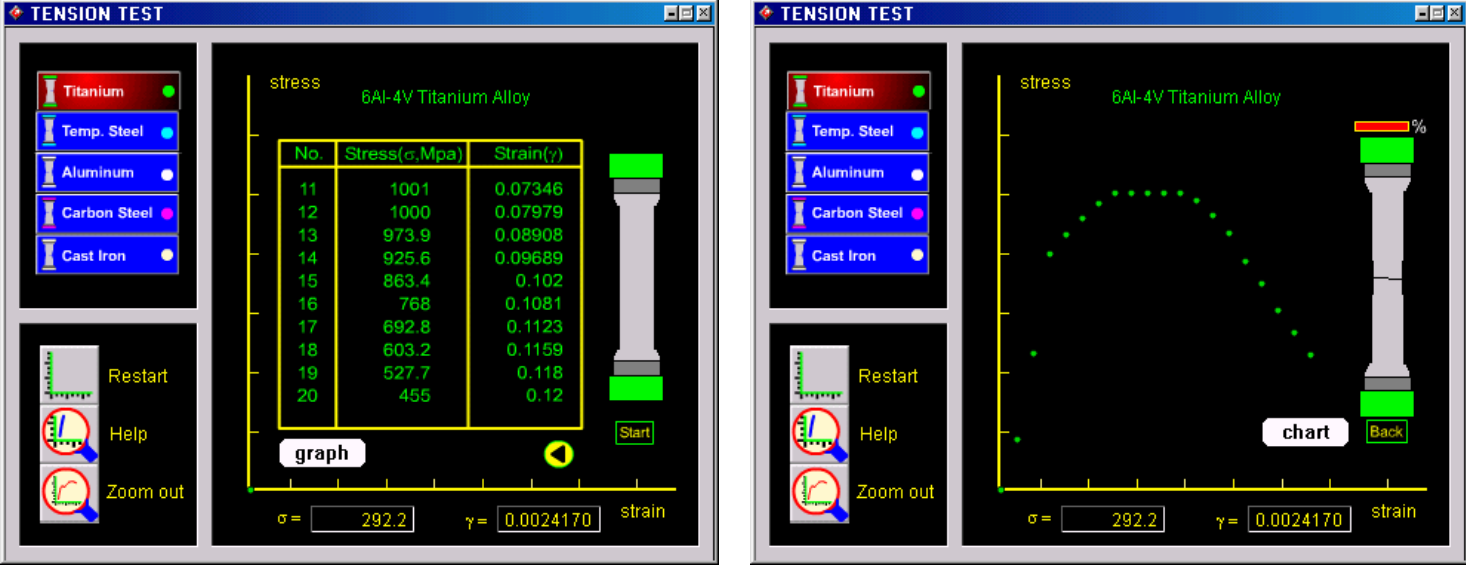

Figure 3 Titanium Data (Points 11-200)

Figure 4 Simulated Tension Test (Titanium)
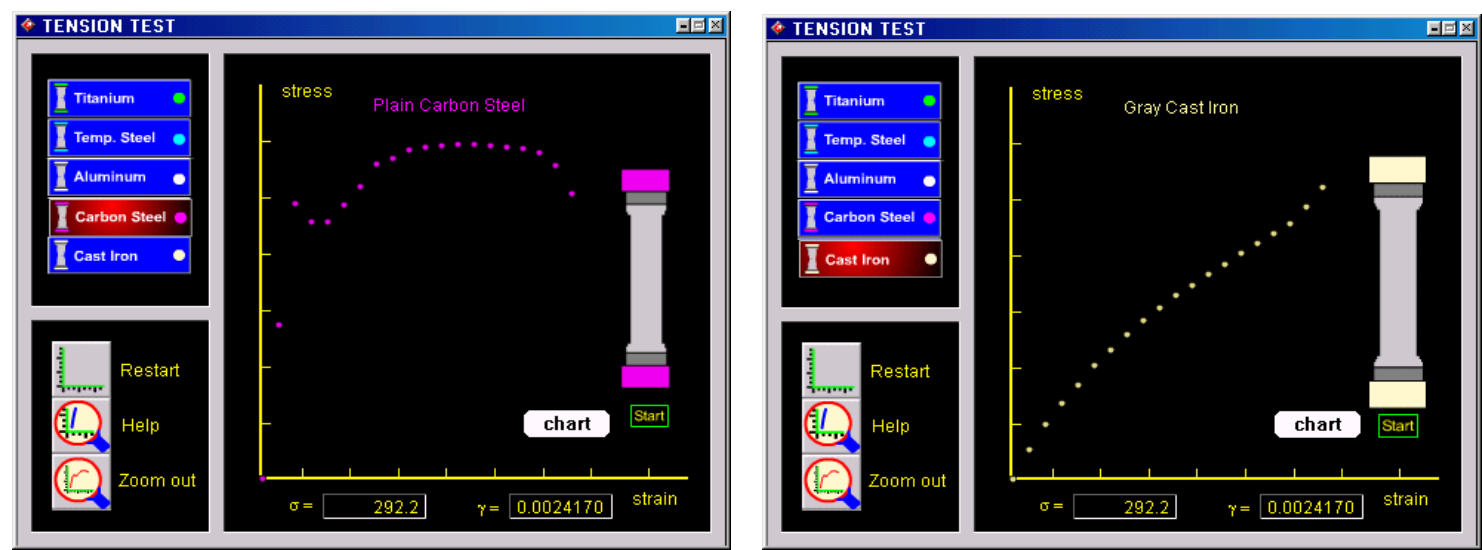

Figure 5 Stress-Strain Graph (Mild Steel) Figure 6 Stress-Strain Graph (Cast Iron)

on the screen when the user clicks on the "graph" icon. By clicking on the "start" icon (Figure 1), the user can view a simulated tension test on the screen in which the specimen in the right window (Figure 1) elongates gradually till it fails. A small window (Figure 4) appears on the top of the specimen that shows the elongation in percent at various stages of the simulated tension test. The user can view the simulated test as many times as desired. Each time the "Restart" icon is clicked, the stress-strain graph is erased and a new graph is drawn. Also, the user can change the size of the graph by activating the "Zoom out" icon. Figure 5 shows the stress-strain 
graph for typical carbon steel (or mild steel), while Figure 6 shows a similar graph for cast iron steel. A comparison between these two graphs illustrates that carbon steel is much more ductile and has a well-defined yield strength than cast iron, as one can see from actual laboratory tests. A review of the corresponding numerical values in the tables (not shown in figures) reveals that cast iron is a stronger but more brittle material than mild steel. Specifically, the cast iron in Figure 6 reaches the peak strength of $416 \mathrm{MPa}$ at $0.432 \%$ axial strain at failure. The corresponding values for mild steel are $296 \mathrm{MPa}$ and $26 \%$ axial strain, respectively. Comparatively, the peak strength of titanium is about $1,000 \mathrm{MPa}$, at the axial strain-level of $6.5 \%$, indicating that it is the strongest of the three materials (mild steel, cast iron, and titanium) in terms of peak strength. The residual strength of titanium at failure is $455 \mathrm{MPa}$ at $12 \%$ axial strain. One can also use the tabulated values to determine the Young's modulus, E. Taking the initial slope of the stress-strain diagram as a measure of $\mathrm{E}$, the following values are obtained: Titanium $=114 \mathrm{GPa}$, Tampered Steel $=200 \mathrm{GPa}$, Aluminum $=69 \mathrm{GPa}$, Carbon Steel $=195 \mathrm{GPa}$, and Cast Iron $=195 \mathrm{GPa}$, indicating that steel is the stiffest and aluminum the most flexible material, of the five materials selected, in terms of Young's modulus. Also, the user can easily notice that although the peak strengths of tampered steel, mild steel and cast iron are significantly different, their elastic moduli are quite close. The Young's modulus values obtained from the tables in the module are realistic values and within the range of values found in the published literature (Gere and Timoshenko, 1997).

\section{BENDING MODULE}

When a beam is subjected to forces or couples, stresses and strains are created throughout the interior of the beam due to bending. Since these stresses are caused by bending, they are usually known as "bending stresses." Both normal and shear stresses are induced by bending. For nonuniform bending, these stresses are different at different locations along the length of a beam, and at a given location they vary from one point to another on the cross-section of the beam. Therefore, the design of a beam requires a clear understanding of the bending stresses, particularly the determination of maximum normal (both tensile and compressive) and shear stresses. The "Bending Module" is designed to illustrate the aforementioned elements of bending stresses. The module considers a simply supported beam subjected to a concentrated load in the middle (Figure 7). The magnitude of the load can be increased by the user from 1000 lbs to $2000 \mathrm{lbs}$ by dragging the icon located below the beam in the left window (Figure 7 or Figure 8). An increase in the magnitude of the load causes an increase in deflection of the beam and stresses within the beam. The module simulates these features in a realistic manner; in Figure 7 when the load magnitude is small the deflection is small and the stress cloud is invisible, while in Figure 8 the deflection is much larger and the stress cloud (shown in color) is clearly visible. Likewise, the span length can be increased or decreased within the specified limits (6 ft to $12 \mathrm{ft}$ ) by dragging the length icon. Two different cross-sections are considered; the hollow cross-section is activated by clicking on the right diagram located at the top right window (Figure 7 or Figure 8), while the solid section is activated by clicking on the left diagram in the same window (Figure 9). Illumination (for e.g., Figures 7 and 9) of the respective window shows the cross-sectional shape that is active. The cross-sectional dimensions can be changed within the specified limits by dragging the icon located just below the cross-section. For simplicity, the aspect ratio (height/width) is kept constant at 2. For a given selection of load magnitude, span length and cross-sectional dimensions, the maximum normal $(\sigma)$ and $\operatorname{shear}\left(\tau_{\mathrm{xy}}\right)$ 

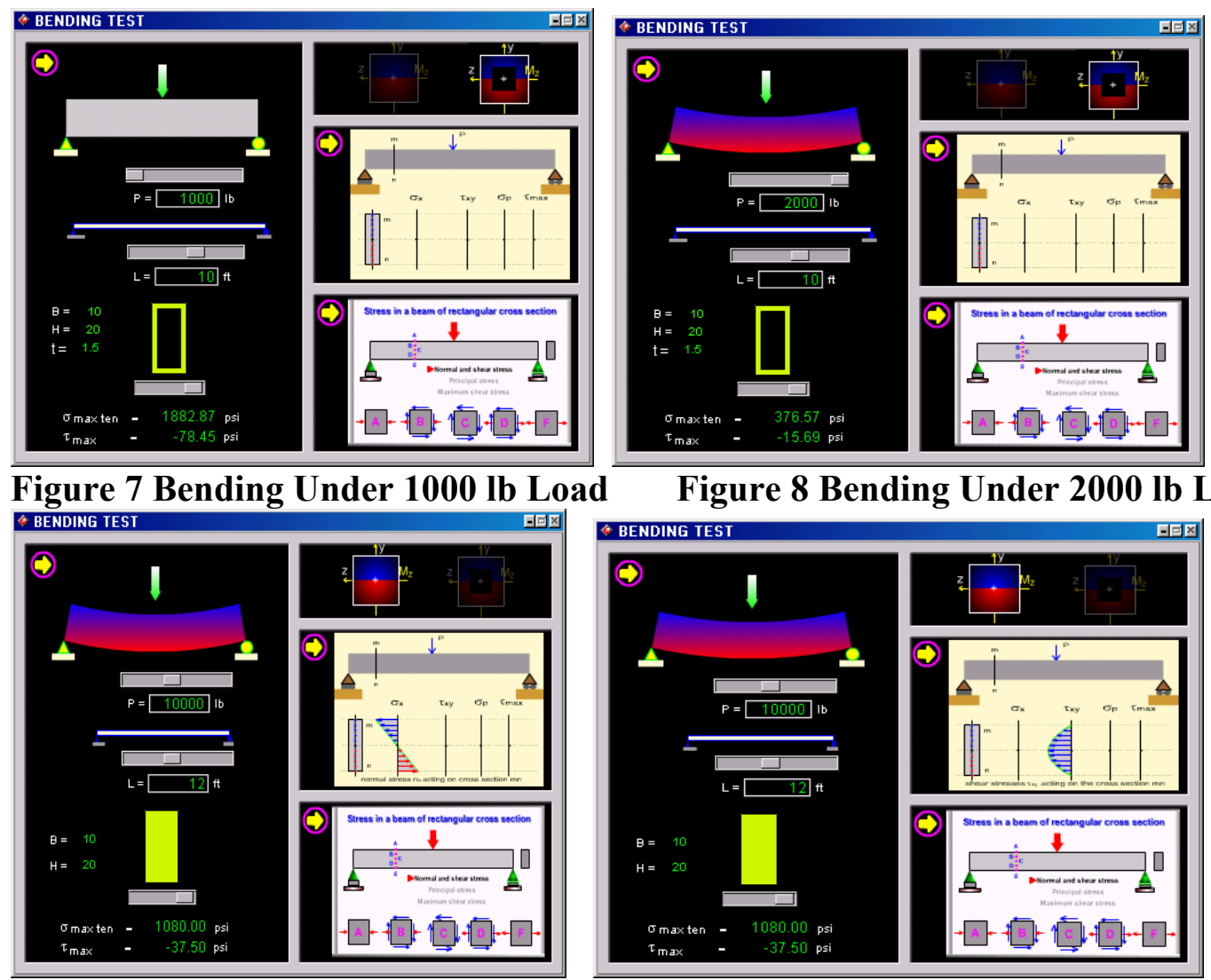

Figure 8 Bending Under 2000 lb Load

$\underset{\text { Figure } 9 \text { Variation of } \sigma \text { Along Depth }}{\text { GEEDIIG IEST }}$

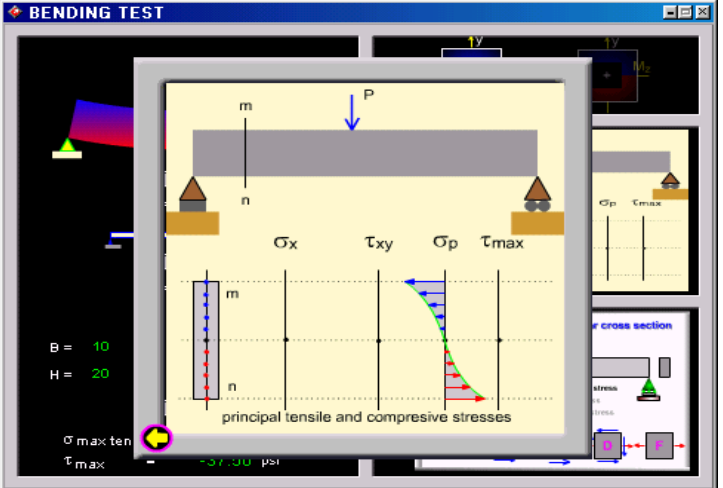

Figure 11 Close Up View of $\sigma_{p}$

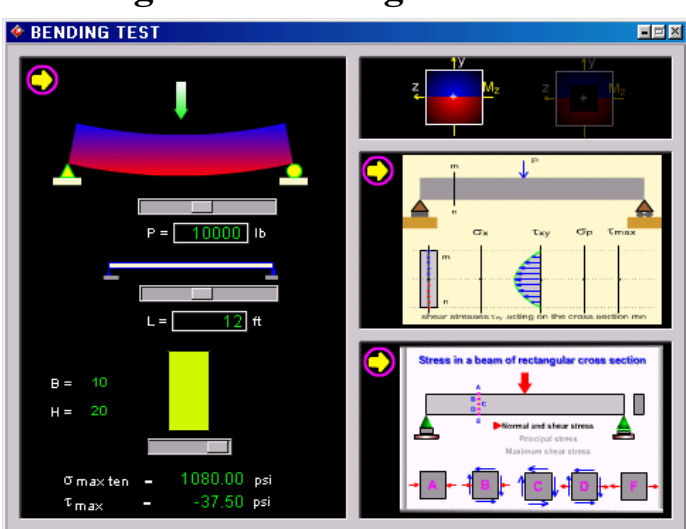

Figure 10 Variation of $\tau_{\mathrm{xy}}$ Along Depth

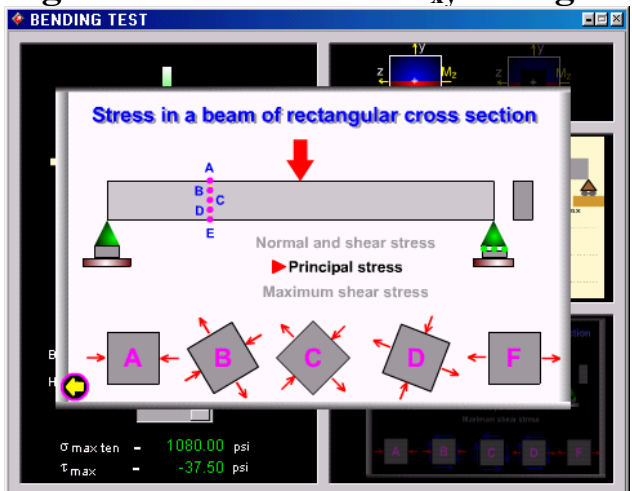

Figure 12 Orientation of Stress Elements

stresses are displayed at the bottom of the left window. This is a useful feature because these values are used in designing a beam. The user can use this feature to examine how maximum normal stress and maximum shear stress change with such factors as load, span length and crosssectional dimensions and shapes.

The two right windows also provide very useful information. The middle window has an option to display the variations of normal stress $(\sigma)$, shear stress $\left(\tau_{\mathrm{xy}}\right)$, principal stress $\left(\sigma_{\mathrm{p}}\right)$ and maximum shear stress $\left(\tau_{\max }\right)$ along the depth of the beam for a selected load, span length and cross-section. One stress component can be displayed at a time and the desired component can be selected by clicking on the stress symbol in this window. Figures 9 and 10 show the variation 
of $(\sigma)$ and $\left(\tau_{x y}\right)$, respectively, as an example. It is seen that the variation of $\sigma$ is linear with maximum compression (blue arrows) at the top and maximum tension (red arrows) at the bottom, while the variation of $\tau_{\mathrm{xy}}$ is parabolic with maximum stress at the mid-height. A close up view of the stress variation can be displayed by clicking on the yellow arrow located at the top left corner of this window (see Figure 11). Another important feature of this module is the display of orientation of stress elements at five selected points along the depth of the beam, one point in the middle and two points above and two points below the mid-point. Normally this window displays the normal and shear stresses acting at these points (see Figures 7 through 10). However, two other stress components, principal (normal) stress and maximum shear stress, can also be displayed by clicking on the yellow arrow located at the top left corner of the bottom right window (for e.g., Figure 10). Figure 12 displays the orientation of principal (normal) stresses at the five selected points noted above. The user can return to the main window by clicking on the yellow arrow located at the left bottom corner (Figure 12).

\section{TORSION MODULE}

This module simulates the torsional behavior of circular (solid, hollow, and hollow with a slit running along its whole length) shafts. Only pure torsional problems are considered, for simplicity. Conceptually, this module is similar to the "Bending Module," except it deals with shear stresses induced by pure torques and no bending effects are considered. The main window is divided in to five sub-windows. Parameters (geometry and applied torque) defining the problem are shown in the first two windows, while the solutions (shear stress $(\tau)$, shear strain $(\gamma)$, and angle of twist $(\phi))$ are displayed in the fourth window, and the equations used to determine these quantities are shown in the fifth window. Typical stress-strain response obtained from a laboratory test involving a circular shaft subjected to a torque is displayed in the third window, in terms of shear stress $(\tau)$ and shear strain $(\gamma)$, to help understand the definition of shear modulus $(\mathrm{G})$ and yield strength.

The shaft geometry (solid or slit hollow) can be selected by clicking on the appropriate box located at the bottom right part of the first window; in Figure 13 the "solid shaft" option is selected as an illustration. The shaft radius can be selected within the specified limits (2 to 5 inches) by sliding the radius icon as desired. Likewise, the magnitude of the applied torque can be selected within the limits by adjusting the torque ("T") icon in the same window. For each selection of shaft geometry and torque, the results $(\tau, \gamma$, and $\phi)$ displayed in the forth window change, giving the user an opportunity to observe the relationships between different parameters (e.g., T and $\phi$ ). The user can observe the variation of shear stress $(\tau)$ along the shaft diameter by clicking on the arrow in the third window (Figure 14). It is seen that the shear stress is always zero at the center of the shaft, is maximum at the outer surface, and it varies linearly along the radius. The main windows are restored by clicking on the "Back" icon (Figure 14). The user can also view the effect of torque application (rotation of the shaft) by clicking on the arrow in the first window (Figure 15). Again, the main windows can be restored by clicking on the "Back" icon. Figures 16 and 17 show similar results for a hollow shaft with a slit. By comparing Figures 15 and 17 the user can easily verify the fact that the hollow circular shaft with a slit (or an open section) is much weaker than a hollow shaft. In order to further appreciate this concept, an option is provided in the module to close the slit by welding. This option is activated by clicking on the "Weld" icon located in the third window. The corresponding results are 

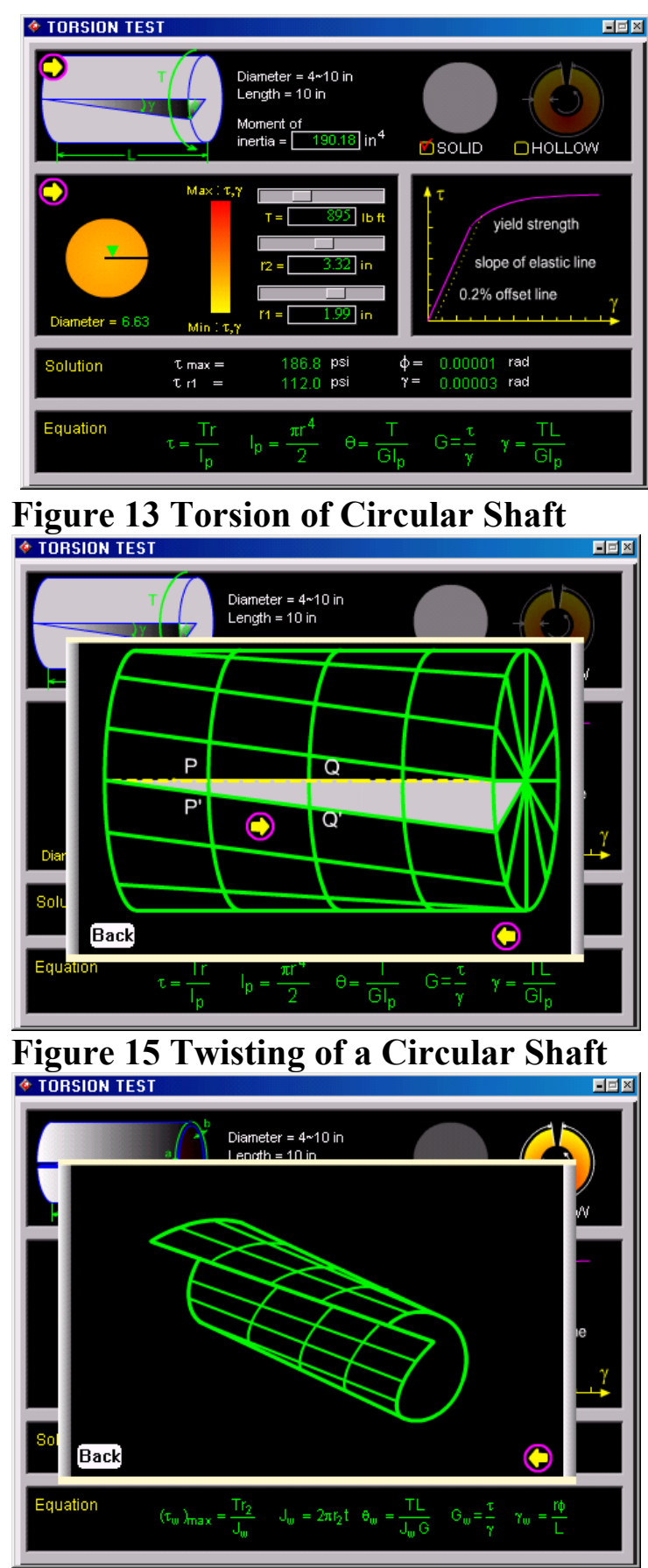

Figure 17 Twisting of Shaft with a Slit

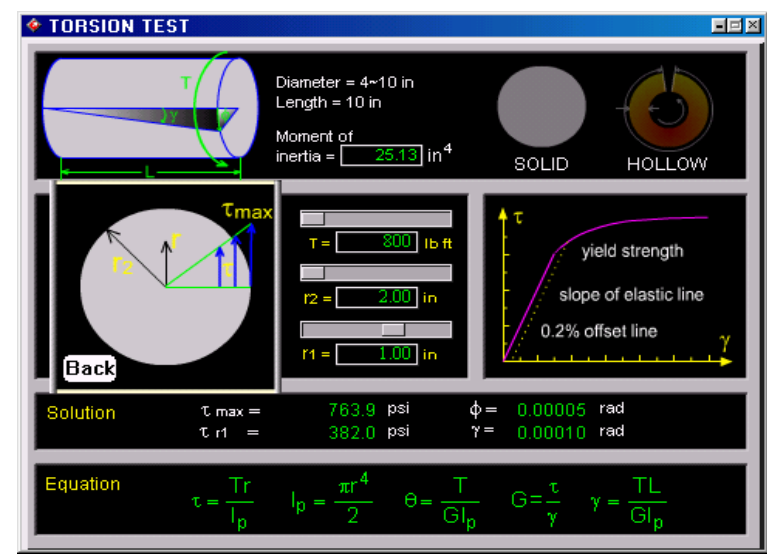

Figure 14 Distribution of $\tau$ Along Shaft Radius

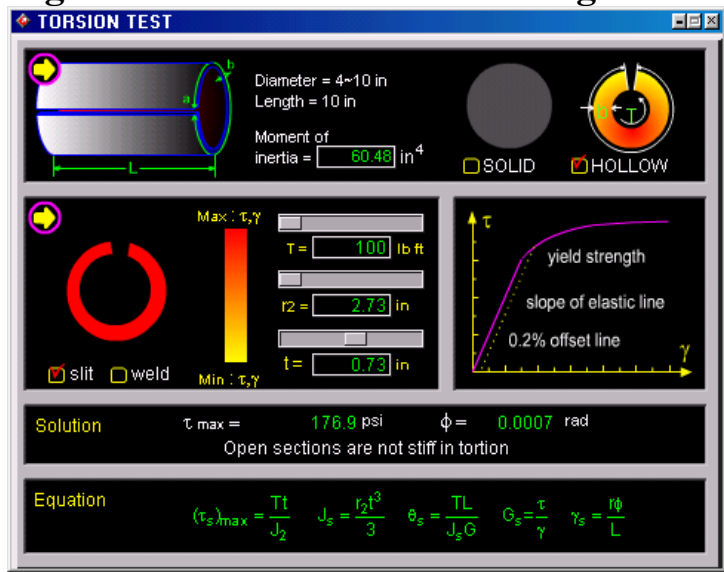

Figure 16 Torsion of Hollow Shaft with a Slit

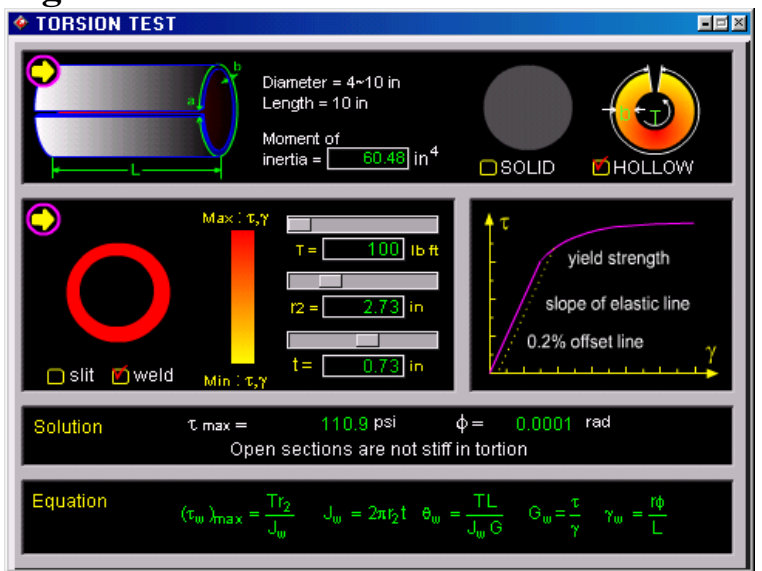

Figure 18 Torsion of a Hollow Circular Shaft

presented in Figure 18. A comparison of Figure 16 with Figure 18 shows that the maximum shear stress decreases from 176.9 psi to 110.9 psi by closing the slit by welding. The corresponding angle of twist also decreases very significantly (from $0.0007 \mathrm{rad}$ to $0.0001 \mathrm{rad}$ ), as expected. The theory of torsional shear stresses for open sections is not discussed in the class, but is coded in the module, and works in the background. However, the display of the results does illustrate that open sections are very weak when subjected to torsion, in comparison to the 
corresponding closed section. So if the weld fails, then the stresses and twist deformations increase significantly, which is an important fact to be appreciated by the designer.

\section{IMPACT}

Although the virtual laboratory modules discussed above were developed with the goal of making them a useful tool to enhance the understanding of theoretical concepts taught in the Strength of Materials course, the level of impact can vary from student to student. So far, we have received only informal feedback from selected students who have used them as part of a limited application. Most of the students commented that these modules positively impacted their learning, and they found the modules particularly useful when the underlying theoretical concepts had already been taught in the class. Specifically, these modules not only further reinforced these concepts, but also provided an opportunity to view graphically and pictorially how the results varied when the input parameters were varied with a practical range. Thus, they were able to appreciate the sensitivity of the problem to input parameters. Overall, the students commented that this made the learning experience fun. These comments are quite consistent with our goals we had set while undertaking this project. We plan to conduct a more formal survey when these modules are used this Spring semester (2002), and we would report the results of this survey in a future publication.

\section{CONCLUDING REMARKS}

In this paper three virtual laboratory modules have been presented that were developed to enhance the understanding of concepts taught in the undergraduate Strength of Materials course. In preparing these virtual experiments, actual test data was used with interpolation capability to generate results and graphical plots of behavior that are realistic in nature. The Material Module can be used by students to simulate a tension test, and to compare the mechanical properties (Young's modulus, failure strength, and ductility) of different materials obtained from such a test. This module is expected to enhance the understanding of how and why one material behavior differs from the other. The Beam Module illustrates the variations in normal and shear stresses induced by bending of a simply supported beam of rectangular cross-section. Students can use this module to verify the assumption that plane sections remain plane after bending and to illustrate the influence of the change in cross-sectional shape (solid, hollow) and size on the beam bending behavior. The Torsion Module simulates the torsional behavior of solid and hollow circular shafts. Students can use this module to conduct virtual experiments to demonstrate why open sections perform poorly when subjected to torsion in comparison to solid sections. An informal survey indicates that these modules can positively impact the learning experience of students in a Strength of Materials course and make learning an enjoyable experience. A formal survey concerning the impact of these virtual modules will be conducted this Spring semester, and the results will be presented in a future publication.

\section{ACKNOWLEDGEMENTS}

Development of the virtual laboratory modules was pursued with internal funding provided by Provost's Office of the University of Oklahoma. The authors would like to gratefully acknowledge this support. 


\title{
REFERENCES
}

Gere, J.M., and Timoshenko, S.P. (1997), "Mechanics of Materials." Fourth Edition, PWS Publishing Company, Boston, Massachussetts.

Kukreti, A.R. (1996), "A New Approach to Teach the Undergraduate Rigid Body Mechanics Course," Thirty First Midwest Section Conference, ASEE, University of Tulsa, Tulsa, Oklahoma, April 10-12.

Sun, Q., Stubblefield, and Gramoll, K. (2000) "Internet-based Simulation and Virtual City for Engineering Education," Proceedings of the 2000 ASEE Annual Conference, St. Louis, MO, June 18-21.

Zaman, M., and Kukreti, A.R. (2000), "Impact of Computer-Based Learning Tools in Rigid Body Mechanics," Proceedings of the 2000 ASEE Annual Conference, St. Louis, Missouri, June $18-21$.

\begin{abstract}
ANANT R. KUKRETI
Anant R. Kukreti is a Professor of Civil Engineering and Head of the Department of Civil and Environmental Engineering at University of Cincinnati. He was a faculty member at the University of Oklahoma for 22 years before moving to University of Cincinnati in August 2000. He has won numerous teaching awards, which include the Burlington Northern Foundation Teaching Award, Regents Award for Superior Teaching, ASEE Midwest Section Outstanding Teaching Award, and the ASEE Fluke Corporation Award for Innovation in Laboratory Instruction. At University of Oklahoma he also received the David Ross Boyd Professorship.
\end{abstract}

\section{MUSHARRAF ZAMAN}

Musharraf Zaman is a Professor of Civil Engineering and Environmental Science at the University of Oklahoma (OU). Since joining OU in 1982, he has taught a large number (18) of courses, and has introduced six new graduate courses. His teaching contributions have been recognized by the ASEE through its Midwest Section Outstanding Teaching Award and the Agilent Technologies Award for Excellence in Laboratory Instruction. He also has received the Presidential Professor Award at OU that recognizes and rewards faculty members who meets the "very highest standards of excellence."

\section{KURT GRAMOLL}

Kurt Gramoll is the Hughes Centennial Professor of Engineering and Director of the Engineering Media Lab at the University of Oklahoma. He has developed and published CDs and web-based sites for engineering education, K-12 instruction, and training in industry. He has started two multimedia companies for the development and distribution of technical electronic media. Dr. Gramoll received his B.S. degree in Civil engineering and M.S. degree in Mechanical Engineering, both from the University of Utah. He received his Ph.D. in Engineering Science and Mechanics from Virginia Tech. Previously, he has taught at Univ. of Memphis and Georgia Tech.

\section{JI-HOON LEE}

Former Graduate Research Assistant in the School of Aerospace and Mechanical Engineering at the University of Oklahoma, Norman, Oklahoma. 